\title{
вмJ Global Health Africa is not a museum: the ethics of encouraging new parenting practices in rural communities in low-income and middle-income countries
}

\author{
Ann M Weber (D) , ${ }^{1}$ Yatma Diop, ${ }^{2}$ Diane Gillespie, ${ }^{3}$ Lisy Ratsifandrihamanana, ${ }^{4}$ \\ Gary L Darmstadt (i) ${ }^{5}$
}

To cite: Weber AM, Diop Y, Gillespie D, et al. Africa is not a museum: the ethics of encouraging new parenting practices in rural communities in lowincome and middle-income countries. BMJ Global Health 2021;6:e006218. doi:10.1136/ bmjgh-2021-006218

Handling editor Seye Abimbola

Received 17 May 2021 Accepted 29 June 2021

Check for updates

(c) Author(s) (or their employer(s)) 2021. Re-use permitted under CC BY-NC. No commercial re-use. See rights and permissions. Published by BMJ.

${ }^{1}$ School of Public Health, University of Nevada, Reno, Nevada, USA

${ }^{2}$ Human Development and Family Studies, Michigan State University, East Lansing, Michigan, USA

${ }^{3}$ Emeritus, Community Psychology, University of Washington, Bothell, Washington, USA

${ }^{4}$ Centre Médico-Educatif "Les Orchidées Blanches", Antananarivo, Madagascar ${ }^{5}$ Global Center for Gender Equality, Department of Pediatrics, Stanford University School of Medicine, Stanford, California, USA

Correspondence to Dr Ann M Weber; annweber@unr.edu

\section{SUMMARY}

The Nurturing Care Framework for Early Childhood Development urges stakeholders to implement strategies that help children worldwide achieve their developmental potential. Related programmes range from the WHO's and UNICEF's Care for Child Development intervention, implemented in 19 countries, to locally developed programmes, such as non-governmental organisation Tostan's Reinforcement of Parental Practices in Senegal. However, some researchers argue that these programmes are unethical as they impose caregiving practices and values from high-income countries (HICs) on lowincome communities, failing to consider local culture, communities' goals for their children and generalisability of scientific findings from HICs. We explore these criticisms within a public health framework, applying principles of beneficence, autonomy and justice to the arguments. To facilitate the change communities themselves desire for their children, we recommend that practitioners codevelop programmes and cooperate with communities in implementation to harness local beliefs and customs and promote evidence-based and locally adapted practices.

\section{INTRODUCTION}

Despite significant progress in reducing child mortality globally, an estimated 250 million children in low/middle-income countries (LMICs) are failing to achieve their developmental potential. ${ }^{1}$ Recent evidence demonstrates the relative invariance in children's potential to achieve neurodevelopmental milestones across diverse cultural settings when nutritional and health needs are met. ${ }^{2}$ In The Lancet Series on Advancing Early Childhood Development, nurturing care-which promotes 'children's health and nutrition, protects children from threats, and gives them opportunities for early learning through affectionate interactions and relationships'-was identified as a cornerstone for programmes aiming to promote early childhood development (ECD) globally. ${ }^{34}$ The Nurturing Care
Summary box

As millions of children in low-income and middleincome countries are failing to thrive, local leaders and stakeholders are urged to implement policies and programmes to help children achieve their developmental potential, based on scientific research from mostly high-income countries.

- Some researchers argue that many of these programmes are unethical in that they impose caregiving practices and values from the west, are insensitive to the local culture, and fail to consider what the communities would want for their children if asked.

- Given the momentum in implementing and scaling programmes that encourage caregivers to engage in responsive interaction with young children in countries worldwide, it is critical to reflect on whether policy and programmes are aligned with the needs, values and circumstances of the communities they aim to serve.

- We make recommendations for practitioners to harness the integrity of existing local beliefs and customs, promote evidence-based and locally adapted practices, and cooperate with communities in facilitating the social change communities themselves desire for their children.

Framework, launched in 2018, urges stakeholders everywhere to design and implement strategies to help children achieve their full potential. ${ }^{5}$ This call to action is particularly relevant in sub-Saharan Africa, where children are estimated to be the most disadvantaged among LMICs on multiple indicators of ECD and care. ${ }^{6}$ For example, about $61 \%$ of children 3-4 years of age in the region were rated as developmentally on track for school compared with $75 \%$ on average in LMICs; only $24 \%$ had ever attended an early care and education programme (vs 39\%); and $47 \%$ were exposed to adequate home stimulation during early childhood (vs 69\%). Critically, 
children born in 2020 in sub-Saharan Africa are expected to achieve only $40 \%$ of their potential productivity as future workers (compared with $75 \%$ for children born in North America), due in part to their increased risk of poor health, nutrition and inadequate student learning outcomes. $^{7}$

Nonetheless, ECD programmes with a focus on 'opportunities for early learning' have been harshly criticised by some researchers. For example, UNICEF's signature ECD programme, Care for Child Development (CCD), ${ }^{8}$ which has been integrated into existing services in at least 19 countries, ${ }^{9}$ and a locally developed parenting programme in rural Senegal, the Reinforcement of Parental Practices (RPP) programme, ${ }^{10}$ were effectively charged with adopting a neo-colonial form of development by promoting high-income country (HIC) parenting styles in communities with rural, subsistence lifestyles. ${ }^{11}$ The researchers questioned the generalisability of scientific evidence from mostly Western countries used to rationalise parenting programmes in LMICs (eg, the importance of talking with children). They argued that such programmes fail to consider what communities want for their children and supplant traditional practices that are beneficial to children, thereby risking more harm than good.

While institutional review boards (IRBs) provide direct oversight of research practices to protect people from harm, they may not be equipped to accurately assess risks associated with promoting behaviour change where cultural practices and community values need full consideration. Moreover, IRBs do not oversee programme implementation in the absence of evaluations involving human subjects research. IRBs rely on ethical principles such as those set forth in the 1974 Belmont Report, which provides guidelines to assure that human subjects research is conducted in accordance with the principles of beneficence, respect for autonomy and justice. Herein, we use a public health framework to explore these principles as they relate to the RPP specifically, because the programme was a direct target of criticism, and to parenting programmes more broadly, because the RPP represents an ever-expanding number of parenting programmes being implemented and evaluated globally. We begin by describing the context, development and implementation of the RPP in rural Senegal. We discuss each of the principles of beneficence, autonomy and justice in turn, and end with recommendations for upholding ethical principles when implementing parenting programmes for the advancement of ECD in LMICs-principles through which to assess the ethical design of any public health programme.

\section{RPP PROGRAMME}

The RPP programme is run by the non-profit organisation, Tostan, headquartered in Senegal since 1991 and operating out of five West African countries with an almost allAfrican staff working directly with partner communities.
Since its founding, about 3000 rural communities have participated in Tostan's foundational 3-year human rights-based education programme, the Community Empowerment Programme (CEP), which preceded the RPP. ${ }^{13}$ Communities set a collective vision for their future well-being while learning about democracy, human rights, problem-solving, hygiene and health. Community members openly debate whether traditional practices help or hinder their well-being and learn practical skills in reading, mathematics and project management to help achieve their long-term goals. One professed goal of CEP participants throughout West Africa is for their children to succeed in school. ${ }^{13}$ Increased parental attention to and support of children both before and as they attend school are important intended outcomes of Tostan's CEP. For example, communities may seek government funds to build schools or hire teachers; parents may relieve children from household chores to study.

The majority of Senegalese children living in CEP communities are functionally illiterate. A 2014 study found that after 6 years of primary education, $75 \%$ of children from the poorest quintile of Senegalese households were unable to read with sufficient skill for school continuation. ${ }^{1415}$ Correspondingly, parents had informed Tostan facilitators of their children's struggles in school. In response, Tostan's programming staff consulted former CEP participants on how to proceed. Any new programme needed to preserve cultural values and practices that were meaningful within the local context and had emerged, through consensus, from dialogues in CEP classes. The resulting programme (the RPP) was designed in 2012 with the help of Senegalese staff and an international child development expert and aimed to stimulate communities to explore ways to promote children's learning and empower parents to help their children succeed in school and in life. Intended to leverage mathematics and literacy skills that parents gained during the CEP, the RPP builds on Tostan's model of community-led change, enabling participants to apply new knowledge about ECD within the context of their collective vision of what's important to their children's well-being and reflecting their values.

Tostan facilitators, who live in communities during the 10-month RPP, teach caregivers, community leaders, school teachers and imams (Muslim religious leaders) about the developing brain and the importance of engaging in interactive and responsive talk with infants. The course includes traditional Senegalese infant massage, theatre, role play, singing and dancing in group sessions held three times a week and bi-monthly home visits. Tostan designed and distributed over 350 000 colourfully illustrated children's books, previously unavailable, written in national languages (eg, Wolof, Mandinka and Pulaar) for parents to read to their children or engage in dialogue related to the locally relevant stories and illustrations (ie, dialogical reading). Further, participants collaborate with Community Management Committees and hold teachers and school principals accountable for their children's education. 
At the time the RPP was developed, parenting education programmes with promising evidence of impact on ECD outcomes for at-risk infants and toddlers ${ }^{16}$ included USA's Parents as Teachers home-visiting programme ${ }^{17}$ and Reach Out and Read's paediatric literacy programme, ${ }^{18}$ as well as Jamaica's Home Visit programme (now known as Reach Up). ${ }^{19}$ More recently, a systematic review of parenting interventions delivered during the first 3 years of children's lives included nine (of 102) studies in six African countries (of 33 countries globally). ${ }^{20}$ The African programmes ranged from an adaptation of the 2-year Reach Up programme in rural Madagascar, ${ }^{21}$ which was not found to change ECD outcomes, to an 8-week book-sharing training programme for caregivers living in a peri-urban settlement in South Africa, ${ }^{22}$ which was shown to impact children's language development and sustained attention. In rural Uganda, a programme similar to the RPP in design was found to increase children's cognitive and language scores in the programme group compared with control. ${ }^{23}$ These programmes resemble a public health model that aims to address risks faced by families living in poverty that are associated with delayed ECD and poor school performance.

\section{BENEFICENCE}

The principle of beneficence embodies our collective obligation to bring about good in all our actions, while minimising or preventing harm. In public health, we have decided that the benefits of immunising against preventable diseases outweigh possible harm and set universal vaccination as an attainable goal for all children everywhere. ${ }^{24}$ But does this moral imperative to act hold for parenting programmes that aim to address children's early development? The 2030 Sustainable Development Goal (SDG) 4.2, which was adopted by 193 United Nations member states, suggests that it does. The goal states that countries should: 'ensure that all girls and boys have access to quality ECD, care and pre-primary education so that they are ready for primary education'. ${ }^{25}$ In formative research, Tostan found that rural Senegalese parents were mostly unaware of ways to promote school success and viewed their teaching role mainly as promoting obedience and respect in their children and teaching life skills (eg, cooking and farming), perceptions that are shared by caregivers across diverse low-income communities. ${ }^{26}$

While the low literacy in Senegal is likely due in part to challenges in the school system, ${ }^{27}$ children in Tostan CEP communities enter school unprepared for learning to read, having heard and spoken a local language that is different from the language of instruction. This incongruity is a risk for difficulties in school learning — not only in Senegal but in other former European colonies-and more broadly, a risk for children whose mother tongue differs from the institutional language of instruction in their country of residence, such as children of certain ethnic minority groups and refugee or migrant children. ${ }^{28}{ }^{29}$ A lack of reading materials in many low-income households further hinders children from learning to decode letters and gaining phonological awareness in any language. ${ }^{30}$ The lack of access to affordable illustrated books in rural areas misses the opportunity for development of children's capacity for abstraction from two-dimensional illustrations to real life and later to words. ${ }^{31}$ Such deficits put resource-poor children at a disadvantage in learning to read, expand their vocabulary and acquire new knowledge, as compared with children in wealthier welleducated families. ${ }^{32}$ In the USA, the Reach Out and Read ${ }^{18}$ programme provides low-income parents with developmentally appropriate books during routine well-child visits and instructions on how to read aloud to children. The provision of early reading materials and engagement of children in interactive reading activities is expected to benefit disadvantaged children everywhere-whether living in rural African villages or visiting paediatricians' offices in the USA.

Nevertheless, actions taken to change parenting behaviours in order to achieve the SDGs should align with outcomes that matter for any given community, while not obstructing those valued by the community. By overlooking local social, cultural and gender norms, programmes have failed to change behaviours, and in some cases, resulted in unintentional harm. ${ }^{33}$ Some contend that promoting more child-directed talk to improve language and literacy skills in agrarian settings is an example of risking harm by ignoring the importance of communicating with gestures in communities where verbal skills may be less important (eg, for communicating while working in the field).$^{34}$ Studies have shown that the use of gestures coordinated with verbal language is a powerful means of communication. ${ }^{35}$ Research on socioeconomic disparities in early vocabulary acquisition suggests a mutually reinforcing connection between parent's use of gestures and talk with pre-verbal children. ${ }^{36}$ However, the aim of the RPP is not to discourage gestures in situations where they are effective, but rather to augment them by encouraging caregiver talk during daily interactions with infants such as during bathing, massage and dressing, as well as through book-sharing. Furthermore, research in rural Senegalese communities found that a high quantity of child-directed talk by adults was not an entirely foreign practice, but rather an uncommon (or 'positive-deviant') one and not in conflict with local culture. ${ }^{10}$ In fact, enabling communities to adopt uncommon but beneficial behaviours that some community members already practice can be an effective means of facilitating positive change. ${ }^{37}$ Under such conditions, and in keeping with parents' own wishes for their children's educational success, Tostan and others' programmatic actions to help parents prepare their children for school can reflect the principle of beneficence.

\section{RESPECT FOR AUTONOMY}

A concern levied against Tostan's RPP and UNICEF's CCD is that such programmes impose values from HICs, effectively judging resource-poor parents in LMICs for their way of parenting. While caution is certainly needed to avoid imposing foreign ideals, the Tostan programme 
provides an excellent model for how to uphold the principle of respect for communities' autonomy in making decisions concerning their own lives. In the RPP, for example, Tostan facilitators encourage community members to consider their existing practices in light of available scientific evidence and their collective hopes and dreams for their children. Participants reaffirm positive practices they want to retain and are encouraged to identify acceptable practices to replace ineffective or harmful ones (eg, harsh discipline). Importantly, communities are not told to stop practices they value (eg, teaching respect for elders).

However, for any community to make informed decisions about adopting new practices, the science presented must be evidence-based and generalisable to the local context. Research in most western countries has documented that infants who hear more directed, responsive and varied speech from caregivers become more efficient at processing language,${ }^{38}$ learn vocabulary more quickly ${ }^{39}$ and develop stronger language skills. ${ }^{40}$ Children with stronger language skills, in turn, perform better in school. ${ }^{41}{ }^{42}$ Do these associations hold true for children growing up in circumstances very different from those of children on whom the developmental science literature is overwhelmingly based ${ }^{43}$ Research has shown that child-directed speech is an important means by which children learn new words, even in communities where children's language input comes primarily from overheard speech. ${ }^{44}$ In the pre-RPP evaluation, carefully adapted Wolof-language measures were used to demonstrate that, indeed, the amount of talk a child experiences in rural Senegal is associated with their language processing ability, which in turn is associated with the size of their vocabulary. ${ }^{45}$ Additionally, studies of withincountry variation in western countries have shown that despite large differences in parenting practices across cultural groups, 'associations between parenting and child development generalise across cultures, with rare exceptions'. ${ }^{46}$ Finally, the association between poverty and neurodevelopment in very young children is wellestablished. ${ }^{47} 48$ The evidence is increasingly strong for the mediating role of caregiver engagement in explaining the socioeconomic gaps in ECD across diverse global contexts. ${ }^{49-51}$

An additional concern of parenting programmes implemented in agrarian communities is that they ignore the value of children learning from observing parents' activities, which is common for the transfer of certain tasks. However, other forms of learning, especially schoolbased learning, involve verbal reasoning, ${ }^{52}$ a focus area of the RPP. When asked to express their educational goals, adolescents in Tostan CEP communities report wanting to be healthcare workers, teachers, agricultural technicians or religious leaders. Correspondingly, Africa is experiencing rapid economic development, with large numbers of youth migrating to urban centres to train and look for jobs that require school-based skills. ${ }^{53}$ Even in rural communities, there is pressure to replace subsistence agriculture with technological models for farming, placing demands on farmers to be both literate and techsavvy ${ }^{54}$ Cultural psychologist Kagitçibasi stresses that 'the culture gap between traditional childrearing values and the new environmental demands emerging with social change and urban lifestyles may result in disadvantage for the child'. ${ }^{52}$ Kagitçibasi argues that 'What was probably functional at one point in time may not continue to be functional at a later point in time, due to changed circumstances; it may even become dysfunctional'. Similarly, Levine et al reason that 'parental practices that are adaptive or effective under one set of historical conditions may not be so when conditions change' ${ }^{55}$ A child's future today is not necessarily their parent's past.

\section{JUSTICE}

Finally, the principle of justice urges us to treat all people fairly, with equality and impartiality. When we choose to do nothing, we assume the status quo is best for all people involved. However, there is an unfair burden of ill-health and poor development for children living in poverty and whose parents never received a formal school education. ${ }^{14}{ }^{14}$ In the recent systematic review of parenting programmes for children $0-3$ years, a greater effect on cognitive development was found in LMICs compared with HICs. ${ }^{20}$ An earlier review of a wide range of interventions in LMICs that targeted learning outcomes for children $0-8$ years found that child-focused educational interventions had larger effects on the cognitive development of children from low-income compared with high-income families. ${ }^{56}$ Preserving the status quo perpetuates and ultimately widens the inequality gap in child health and development between the educated rich and the uneducated poor, ${ }^{54}$ raising ethical concerns of inaction when action is possible. Encouraging child-directed speech and dialogical reading is just one part of many parenting programmes, which also include vital public health information ${ }^{23}$ to help parents mitigate the effects of poverty and protect their children, such as recommended hygiene practices for preventing childhood diarrhoea and feeding practices for optimal child growth. New evidence for the impact of nutritional supplementation on certain ECD outcomes suggests that children who are the most disadvantaged (ie, are acutely malnourished, live in low socioeconomic status households, whose mothers have low education) may benefit the most. ${ }^{57}$

Yet, it is the messaging around encouraging more verbal engagement and creating opportunities for early learning that are challenged as culturally inappropriate, with their importance to children's development put in question. ${ }^{910}$ When the RPP was evaluated, there was uncertainty about the benefit of the programme in rural Senegal due to the lack of evidence at that time from similar programmes in Africa. If evidence grows that such programmes benefit those most in need and translate into long-term school and economic successes while upholding locally relevant values (eg, obedience 
in children), then we will be ethically obliged to provide the information, just as we do interventions known to prevent disease and disability.

\section{RECOMMENDATIONS}

Given the momentum in implementing and scaling programmes that encourage caregivers to engage in more interactive and responsive interactions with young children in LMICs, it is important to ensure that our desire to help is aligned with the needs, values and circumstances of the communities we work with. Parents in rural low-income communities share a universal value with parents everywhere: they want what's best for their children. However, parental aspirations occur within a sociocultural and economic context that influences what parents can even imagine for their children's academic success. In certain low-income, low-resource contexts where children do not complete their formal education, parents are not actively involved in the skills development that facilitate the integration of their children into social institutions such as school, but rather are focused on meeting their children's physical needs.$^{58}$ In a discussion of the challenges of meeting children's needs in Africa, Marfo et al write that: 'ECD initiatives that focus exclusively on socialization goals for psychological development, culturally appropriate competencies, and school readiness are likely to attain minimal results if they pay little or no attention to children's physical survival and health needs, ${ }^{59}$ Furthermore, in order to improve the adoption of scientific best practices by communities, we need to adapt programmes to the local culture by recognising and integrating existing beliefs, practices, people, context and skills. ${ }^{60}$ Communities may resist or reject recommended parenting practices if they fail to see their own cultural values and traditions integrated in the programme. ${ }^{61}$ To make informed decisions around their children's well-being, communities should be given accurate information and adequate time to prepare and discuss the consequences of acting on that information.

Additionally, it is important to measure culturally relevant skills and outcomes when evaluating parenting programmes. If we only measure constructs that are valued from a western perspective, then negative effects of local consequence may be missed. The growing body of research in LMIC settings, and the development of new measures that are cross-culturally relevant, ${ }^{62} 63$ will continue to reduce the gap in scientific evidence and further our understanding of the generalisability of findings globally.

Finally, it is essential to adopt a set of ethical guidelines-including the principles of beneficence, respect for autonomy and justice-with which to examine parenting programmes, and indeed all public health programmes in LMICs. Community-level programmes should consider ethical issues pertaining specifically to group models, ${ }^{64}$ including sensitivity to social-cultural norms and ensuring equitable representation and inclusion of community members with diverse perspectives. We maintain that the Tostan model of encouraging community members to openly debate their shared values and goals, while learning practical skills and scientific evidence about ECD, is a commendable example. Changes are therefore not promoted externally but are endogenous. Community participatory research and human-centred design are methods that can be leveraged by programme planners to ensure that intended beneficiaries are part of the design process and that their needs and concerns are met.

\section{CONCLUSION}

Sub-Saharan Africa is projected to increase to $>25 \%$ of the world's total under-25 population by 2030 and to expand the size of its workforce in this timeframe by more than the rest of the world combined.$^{65}$ Investments in nurturing care programmes, ${ }^{5}$ including the provision of learning opportunities in the early years, will be necessary for cultivating a productive workforce. However, change will only happen if practitioners harness the integrity of existing local beliefs and traditions, promote evidencebased and locally adapted practices, and cooperate with local communities in facilitating the social change communities themselves desire. Critically, charges of ethnocentricity can backfire, leading educators to, in effect, maintain that local illiteracy and lack of numeracy are part of one's ecological context, which is immutable. This leaves communities bereft of educational opportunities for their children. As a religious leader from the village of Keur Simbara, Senegal told Tostan: 'Africa is not a museum. Life is walking and we must walk with itor we will be left behind'.

Acknowledgements The authors would like to acknowledge the efforts of Molly Melching and Tostan staff to empower families and communities in rural Africa and the research leadership provided by Dr Anne Fernald of Stanford University in the evaluation of Tostan's parenting programme. We thank the Senegal research team for their hard work and local knowledge contributions during the evaluation. We also thank Francesca Moneti, Senior Advisor of Strategy and Programmes at Tostan and Dr Dana McCoy and Mr Jonathan Seiden of Harvard University for their thoughtful and valuable feedback on this manuscript.

Contributors AMW conceived of and drafted the paper. YD, DG, LR and GLD contributed to framing of key points. All authors contributed to editing and finalising the paper. YD was affiliated with Dalberg Global Development Advisors in Dakar, Senegal during the evaluation of Tostan's parenting programme, discussed in the paper.

Funding The authors have not declared a specific grant for this research from any funding agency in the public, commercial or not-for-profit sectors.

Competing interests Coauthor DG is the sibling of Molly Melching, Creative Director of Tostan, the NGO operating one of the programmes discussed in the paper.

\section{Patient consent for publication Not required.}

Provenance and peer review Not commissioned; externally peer reviewed. Data availability statement There are no data in this work.

Open access This is an open access article distributed in accordance with the Creative Commons Attribution Non Commercial (CC BY-NC 4.0) license, which permits others to distribute, remix, adapt, build upon this work non-commercially, and license their derivative works on different terms, provided the original work is 
properly cited, appropriate credit is given, any changes made indicated, and the use is non-commercial. See: http://creativecommons.org/licenses/by-nc/4.0/.

\section{ORCID iDs}

Ann M Weber http://orcid.org/0000-0001-8130-5858

Gary L Darmstadt http://orcid.org/0000-0002-7522-5824

\section{REFERENCES}

1 Black MM, Walker SP, Fernald LCH, et al. Early childhood development coming of age: science through the life course. Lancet 2017;389:77-90.

2 Villar J, Fernandes M, Purwar M, et al. Neurodevelopmental milestones and associated behaviours are similar among healthy children across diverse geographical locations. Nat Commun 2019;10:511.

3 Britto PR, Lye SJ, Proulx K, et al. Nurturing care: promoting early childhood development. Lancet 2017;389:91-102.

4 Richter LM, Daelmans B, Lombardi J, et al. Investing in the foundation of sustainable development: pathways to scale up for early childhood development. Lancet 2017;389:103-18.

5 United Nations Children's Fund, World Bank, World Health Organization. Nurturing care for early childhood development a framework for helping children survive and thrive to transform health and human potential, 2018. World Health organization. Available: https://www.who.int/maternal_child_adolescent/documents/ nurturing-care-early-childhood-development/en [Accessed 02 Feb 2020].

6 Lu C, Cuartas J, Fink G, et al. Inequalities in early childhood care and development in low/middle-income countries: 2010-2018. BMJ Glob Health 2020;5:e002314.

7 World Bank. Human capital index 2020 update: human capital in the time of Covid-19. Washington, DC: World Bank, 2020. https:// openknowledge.worldbank.org/handle/10986/34432

8 Lucas JE. Side by side with responsive parents in the care for child development intervention. early child matters AdV early child DEV, 2016. Available: https://bernardvanleer.org/app/uploads/2016/06/ Early-Childhood-Matters-2016.pdf [Accessed 02 Feb 2020].

9 Lucas JE, Richter LM, Daelmans B. Care for child development: an intervention in support of responsive caregiving and early child development. Child Care Health Dev 2018;44:41-9.

10 Weber A, Fernald A, Diop Y. When cultural norms discourage talking to babies: effectiveness of a parenting program in rural Senegal. Child Dev 2017;88:1513-26.

11 Morelli G, Quinn N, Chaudhary N, et al. Ethical challenges of parenting interventions in low- to middle-income countries. J Cross Cult Psychol 2018;49:5-24.

12 Morelli G, Bard K, Chaudhary N, et al. Bringing the real world into developmental science: a commentary on Weber, Fernald, and Diop (2017). Child Dev 2018;89:e594-603.

13 Cislaghi B, Gillespie D, Mackie G. Values deliberation and collective action: community Empowerment in rural Senegal. Springer, 2016.

14 PASEC MJ. Education system Performance in Francophone SubSaharan Africa. Programme D'Analyse Systèmes Educ CONFEMEN Dakar Sénégal. Published online 2014;2016.

15 Bank W. World Development Report 2018: Learning to Realize Education's Promise The World Bank. 2017.

16 Karoly LA, Kilburn MR, Cannon JS. Early childhood interventions: proven results, future promise. Rand, 2005.

17 Wagner M, Spiker D, Linn MI. The effectiveness of the parents as teachers program with low-income parents and children. Topics Early Child Spec Educ 2002;22:67-81.

18 Klass P, Dreyer BP, Mendelsohn AL. Reach out and read: literacy promotion in pediatric primary care. Adv Pediatr 2009;56:11-27.

19 Grantham-McGregor SM, Powell CA, Walker SP, et al. Nutritiona supplementation, psychosocial stimulation, and mental development of stunted children: the Jamaican study. Lancet 1991;338:1-5.

20 Jeong J, Franchett EE, Ramos de Oliveira CV, et al. Parenting interventions to promote early child development in the first three years of life: a global systematic review and meta-analysis. PLoS Med 2021;18:e1003602.

21 Galasso E, Weber AM, Stewart CP, et al. Effects of nutritional supplementation and home visiting on growth and development in young children in Madagascar: a cluster-randomised controlled trial. Lancet Glob Health 2019;7:e1257-68.

22 Vally Z, Murray L, Tomlinson M, et al. The impact of dialogic booksharing training on infant language and attention: a randomized controlled trial in a deprived South African community. J Child Psychol Psychiatry 2015;56:865-73.
23 Singla DR, Kumbakumba E, Aboud FE. Effects of a parenting intervention to address maternal psychological wellbeing and child development and growth in rural Uganda: a community-based, cluster randomised trial. Lancet Glob Health 2015;3:e458-69.

24 United Nations Children's Fund. World Summit for children. Popul Dev Rev 1990:798-801.

25 General Assembly UN. Transforming our world: the 2030 agenda for sustainable development, 2015. Available: https://www.refworld.org/ docid/57b6e3e44.htm [Accessed 13 Feb 2020].

26 Yue A, Shi Y, Luo R, et al. Stimulation and early child development in China: caregiving at arm's length. J Dev Behav Pediatr 2019;40:458-67.

27 World Bank Group. Systematic country diagnostic of Senegal. World Bank, 2018.

28 Slavin RE, Cheung A. A synthesis of research on language of reading instruction for English language learners. Rev Educ Res 2005;75:247-84.

29 Laitin DD, Ramachandran R, Walter SL. The legacy of colonial language policies and their impact on student learning: evidence from an experimental program in Cameroon. Econ Dev Cult Change 2019;68:239-72.

30 Bus AG, van IJzendoorn MH, Pellegrini AD. Joint book reading makes for success in learning to read: a meta-analysis on intergenerational transmission of literacy. Rev Educ Res 1995;65:1-21.

31 Ganea PA, Pickard MB, DeLoache JS. Transfer between picture books and the real world by very young children. J Cogn Dev 2008;9:46-66.

32 Abadzi $\mathrm{H}$. Efficient learning for the poor: new insights into literacy acquisition for children. Int Rev Educ 2008;54:581-604.

33 Gates MF. Putting women and girls at the center of development. Science 2014;345:1273-5.

34 Rogoff B, Mistry J, Göncü A, et al. Guided participation in cultural activity by toddlers and caregivers. Monogr Soc Res Child Dev 1993;58:i.

35 Goldin-Meadow S, Alibali MW. Gesture's role in speaking, learning, and creating language. Annu Rev Psychol 2013;64:257-83.

36 Rowe ML, Goldin-Meadow S. Differences in early gesture explain Ses disparities in child vocabulary size at school entry. Science 2009;323:951-3.

37 Marsh DR, Schroeder DG, Dearden KA, et al. The power of positive deviance. BMJ 2004;329:1177-9.

38 Weisleder A, Fernald A. Talking to children matters: early language experience strengthens processing and builds vocabulary. Psychol Sci 2013;24:2143-52.

39 Rowe ML. A longitudinal investigation of the role of quantity and quality of child-directed speech in vocabulary development. Child Dev 2012;83:1762-74.

40 Hirsh-Pasek K, Adamson LB, Bakeman R, et al. The contribution of early communication quality to low-income children's language success. Psychol Sci 2015;26:1071-83.

41 Kastner JW, May W, Hildman L. Relationship between language skills and academic achievement in first grade. Percept Mot Skills 2001;92:381-90.

42 Duff FJ, Reen G, Plunkett K, et al. Do infant vocabulary skills predict school-age language and literacy outcomes? J Child Psychol Psychiatry 2015;56:848-56.

43 Henrich J, Heine SJ, Norenzayan A. The weirdest people in the world? Behav Brain Sci 2010;33:61-83.

44 Shneidman LA, Goldin-Meadow S. Language input and acquisition in a Mayan village: how important is directed speech? Dev Sci 2012;15:659-73.

45 Weber A, Fernald A, Diop Y. Real-Time language understanding and vocabulary learning by 2-year-old children living in rural African villages. Philadelphia, Pennsylvania: Paper presented at the: SRCD Biennial Meeting, 2015.

46 Prevoo MJ, Tamis-LeMonda CS. Parenting and globalization in Western countries: explaining differences in parent-child interactions. Curr Opin Psychol 2017;15:33-9.

47 Hackman DA, Farah MJ. Socioeconomic status and the developing brain. Trends Cogn Sci 2009;13:65-73.

48 Nelson CA. An international approach to research on brain development. Trends Cogn Sci 2015;19:424-6.

49 Galasso E, Weber A, Fernald LCH. Dynamics of child development: analysis of a longitudinal cohort in a very low income country. World Bank Econ Rev 2019;33:140-59.

50 Sun J, Lau C, Sincovich A, et al. Socioeconomic status and early child development in East Asia and the Pacific: the protective role of parental engagement in learning activities. Child Youth Serv Rev 2018;93:321-30

51 Rubio-Codina M, Attanasio O, Grantham-McGregor S. Mediating pathways in the socio-economic gradient of child development: 
evidence from children 6-42 months in Bogota. Int J Behav Dev 2016;40:483-91.

52 Kagitçibasi C. Family, self, and human development across cultures: theory and applications. Routledge, 2007.

53 Linares OF. Going to the City ... and coming back? turnaround migration among the Jola of Senegal. Africa 2003;73:113-32.

54 Dutta R. Information needs and information-seeking behavior in developing countries: a review of the research. Int Inf Libr Rev 2009;41:44-51.

55 Levine RA, Dixon S, Levine S. Child care and culture: lessons from Africa. Cambridge University Press, 1996. https://books.google. com/books?id=6SDnB9E7RnIC

56 Rao N, Sun J, Chen EE. Effectiveness of early childhood interventions in promoting cognitive development in developing countries: a systematic review and meta-analysis. Hong Kong $J$ Paediatr 2017;22:14-25.

57 Prado EL, Arnold CD, Wessells KR. Small-Quantity Lipid-Based Nutrient Supplements for Children Age 6-24 Months: A Systematic Review and Individual Participant Data Meta-Analysis of Effects on Developmental Outcomes and Effect Modifiers. Nutrition 2021.

58 Lareau A. Unequal Childhoods: class, race, and family life. 2nd ed., with an update a decade later. University of California Press, 2011.
59 Marfo K, Biersterker L, Sagnia J. Responding to the challenge of meeting the needs of children under 3 in Africa. In: Africa's future, Africa's challenge, 2008: 201-26.

60 Kumar V, Kumar A, Ghosh AK. Enculturating science: communitycentric design of behavior change interactions for accelerating health impact. Elsevier, 2015: 393-415.

61 Harkness S, Super CM, Mavridis CJ. Culture and early childhood development: Implications for policy and programs. In: Handbook of early childhood development research and its impact on global policy. Oxford University Press, 2013: 142-60.

62 Black M, Bromley K, Cavallera V. The global scale for early development (GSED). Early Child Matters 2019;14:80-4.

63 Weber AM, Rubio-Codina M, Walker SP, et al. The D-score: a metric for interpreting the early development of infants and toddlers across global settings. BMJ Glob Health 2019;4:e001724.

64 Jamshidi E, Morasae EK, Shahandeh K, et al. Ethica considerations of community-based participatory research: contextual underpinnings for developing countries. Int J Prev Med 2014;5:1328-36.

65 Leopold TA, Ratcheva V, Zahidi S. The future of jobs and skills in Africa: preparing the region for the fourth industrial revolution. World Economic Forum, 2017. http://www3.weforum.org/docs/WEF_EGW FOJ_Africa.pd 